\title{
Absence from work in relation to length and distribution of shift hours
}

\author{
J. WALKER and GWYNNETH de la MARE ${ }^{1}$ \\ Department of Epidemiology and Preventive Medicine, University of Glasgow
}

\begin{abstract}
Walker, J., and de la Mare, Gwynneth (1971). Brit. J. industr. Med., 28, 36-44. Absence from work in relation to length and distribution of shift hours. A long period on night shift or even permanent night work has sometimes been suggested for those on continuous shift work to allow circadian rhythms to adapt. As the weekly hours of work have been reduced there is some evidence that a permanent night shift is practical, and about $12 \%$ of all shift workers are on this type of work. However, the case for permanent night shift must be established on grounds of both effectiveness and acceptability.

The present study compares the absence experience, including sicknessabsence, of permanent day workers and permanent night workers matched for age and job in three undertakings which contained a range of working conditions.

The question of the relationship between absence from work and total hours worked including overtime has been reopened, and in comparing absence from work according to the type of shift the total hours worked must also be taken into account. The relationship between the average hours when a man was at work and the amount of absence was tested. The men in the three undertakings worked a wide range of voluntary overtime.

The results showed that in two undertakings long-term absence, mainly sickness absence, was higher on the night shift than on the day shift; and, in the third, absence was about the same on the two shifts. As the work load was less in the two undertakings with a higher absence on the night shift it was suggested that selective factors were operating. These results may be contrasted to studies which have compared the absence of rotating shift workers and day workers.

In all three undertakings there was a tendency for absence to be less among high overtime workers than among those who worked medium or small amounts of overtime, although the trends were not consistent. There was no evidence at all that high overtime and absence from work were positively associated.
\end{abstract}

The implications of these results are discussed.

During recent years there has been an increase in the amount of shift working in industry and this has led to greater interest in the human problems associated with abnormal hours. One question which arises is whether shift work affects absence from work, including sickness absence. Reviews of previous research (Andlauer and Fourré, 1962; Menzel, 1962) point to conflicting results, but one pattern which

'Present address: 2 Gibson Place, Howick, New Zealand. tends to emerge is that absence rates are higher among day workers than among shift workers (Wyatt and Marriott, 1953) and the result is confirmed in sickness absence studies (Thiis-Evensen, 1958; Aanonsen, 1964; Taylor, 1967, 1968b). The research has, in general, been carried out on men working rotating shifts, while the present study compares the absence experience, including sickness absence, between permanent night workers and permanent day workers. 
Such a comparison is of practical relevance as about $12 \%$ of all shift workers are on normal night shift (Ministry of Labour, 1965). It is also of theoretical interest as physiologists have sometimes argued (Kleitman, 1952, 1963) that a long period on night shift or permanent night work is to be recommended to allow circadian rhythms to adapt. Experimental evidence shows that the rhythms do adapt to changed time routines when favourable conditions exist (Mills, 1966), and in the working situation Utterback and Ludwig (1949) have shown that a submarine crew who worked a system of three fixed 8-hour shifts synchronized their temperature rhythms with the different time schedules. However, in the industrial situation where night workers often retain some daytime habits such as meal times and take a periodic two-day rest break, complete adaptation is less likely to occur. Teleky (1943), reviewing earlier research, suggested that with heavy physical work adaptation might occur, but on light or sedentary work complete adaptation is less usual, while recent research (van Loon, 1963; Colquhoun, Blake, and Edwards, 1968b) suggests that after a period on nights the amplitude of the temperature rhythm is less but inversion is not complete. The body is considered to be under some stress until adaptation occurs. In the laboratory it has been shown that performance is linked positively to body temperature (Kleitman and Jackson, 1950; Colquhoun, Blake, and Edwards, 1968a), and at work telephonists took longer to answer calls (Browne, 1949), and gas plant operators made more errors in the early morning (Bjerner, Holm, and Swensson, 1955). However, in general, output is similar on the day shift and the night shift on rotating shifts (Ministry of Munitions, 1917; Wyatt and Marriott, 1953), although in the earlier study continuous night work was associated with low output. If there is a case for permanent night shift it has to be established on the grounds of effectiveness and acceptability.

The relationship between hours worked and absence has been re-opened by Buzzard and Liddell (1963), who consider that it is necessary to examine total attendance as well as absence from work, and reference is made to the many early studies which demonstrated that increased attendance led to a higher level of absence (Medical Research Council, 1942). This has not been confirmed recently with respect to sickness absence in relation to overtime (Lokander, 1962; Taylor, 1968a). The present paper examines the relationship between absence from work and attendance including voluntary overtime.

The study was carried out on groups of men in two quite different sections of a large national organization situated in the London metropolitan area. In the first group (A) operatives were involved in sending and receiving messages and the type of work was the same during the day as during the night, although the work load was less by night. In the second group (B) operatives were concerned with the sorting and delivery of messages; the day shift did twice as much of the more arduous delivery and less sorting. For a third group (C) absence records were collected in a large, heavy engineering works in the west of Scotland. The factory was modern and included all the machining operations common to heavy engineering and an assembly line. Work on the night shift was the same as on the day shift except that not all departments operated at night.

\section{Shift systems}

In groups $\mathbf{A}$ and $\mathbf{B}$ the men were allowed to choose whether they worked permanent days or permanent nights, allocation to the preferred duty being by seniority as there was a waiting list for permanent nights. In both groups the day shift worked a variety of hours between 08.00 and 22.00 hours for a 44-hour week including meal breaks. The night shift in group $\mathbf{A}$ worked shifts on alternate nights and in group $B$ on five or six consecutive nights.

Group C worked a 40-hour week, excluding meal breaks, in five shifts on both days and nights. Men were allowed to place themselves on a list to change jobs, and no difficulty was experienced in recruiting a permanent night shift. Group A worked a continuous system while in $B$ and $C$ there was a break at the week-end.

\section{Selection of the men}

The samples of day workers and night workers were selected by matching for age, within three years, and job in groups A and B where the work was the same on both shifts. For group $\mathrm{C}$ it was not possible to match by the same job because few men worked on any one, but the men were allocated to positions on a seven-point skill grade arrived at for payment purposes, and they were matched by age and skill grade. In $A$ and $B$ a minimum of three years' service in the particular job was required, and in $\mathbf{C}$ a one-year period of service. The only other grounds for excluding a man from the sample were that he had not worked the required period on one shift, that his length of service was too short, or it was not possible to find a matched pair. The last case occurred mainly with day workers as the number of night shift workers was less. The matching procedure consisted of selecting a night shift worker and then picking at random a day shift worker from those available.

\section{Absence records and sick pay}

In groups $\mathbf{A}$ and $\mathbf{B}$ a sick pay scheme was in operation, fully protecting the men's normal pay for six months, and half pay was allowed for the next six months. In addition, seven days' paid uncertified sickness leave was permitted in any 12 months, which resulted in nearly all short-term absence being classified in this category. Absence was recorded accurately, as revealed by checking the firm's records against a sample of daily work sheets, and diagnoses from medical certificates were recorded. Absence was monitored systematically and sanctions 
could be applied by withdrawing uncertified sickness privileges and overtime working.

In group $\mathrm{C}$ a voluntary sickness and accident insurance scheme operated which was designed to supplement National Insurance allowances so that total benefits approximated to $75 \%$ of a man's basic wage. Absence from work was recorded by the factory accurately, as checked from the foremen's time sheets, except that some half-day absence was omitted and this error was rectified. Medical diagnoses were obtainable only in some cases. Absence from work was monitored somewhat unsystematically, and warnings and the withdrawal of overtime were among the penalties imposed. In the study all absence was recorded for the sample of men for three years in A and B and for one year in C. Measures of attendance at work were also recorded.

\section{Method}

In this study calendar time has been counted for absences of four calendar days or longer; for absences from halfshift up to three shifts' duration working shifts were counted. Absences due to lateness or early departure, and lost time after a period of three months, have been omitted. In order to describe absence behaviour a variety of indices are required; accordingly, the following prevalence rates, similar to some of those used by Gordon, Emerson, and Pugh (1959), are shown in the Tables. Variations from the standard method of computing annual rates occurred, as in groups $A$ and $B$ the rates in the Tables are generally the average of three years, and no absence from work has been counted more than once. In addition to the rates shown below, the annual prevalence rates (persons) were calculated, but as the results were similar to the annual prevalence rates (spells) they have been omitted from the Tables. The proportion of time lost has been calculated on an hourly basis rather than shifts because the number and length of the shifts differed in the work groups.

Long absence (LA) over 3 shifts' duration:

1. Annual prevalence rate (spells)

2. Average duration per spell

3. Average duration per person

Short absence (SA) under 4 shifts' duration:

4. Annual prevalence rate (spells)
Total absence:

5. Proportion of time lost: working hours lost as a percentage of hours planned (excluding overtime)

\section{Results}

Age

Table 1 shows the absence rates of the men aged under 40 and those of 40 and over in the three groups. Absence rates have generally been kept separate in the Tables as trends were not always consistent in the different work groups.

Inspection suggests that the younger men have more spells of long absence than the older men but the average length per spell is less, and the younger men also have an appreciably higher incidence of short-term absence. The total absence rates are higher for the young men, but this is partly influenced by the arbitrary point at which time lost through long absences ceases to be counted - in this case three months - which has a greater effect on the rates for the older men. The results are consistent in the three working groups and follow the established pattern of absence in relation to age, except that the number of long-term absences has generally been found to increase with age (London Transport Executive, 1956). However, changes in the pattern of longer absences with age may be occurring as Raffle (1970), in the same organization, finds that the number of longer absences of younger men has increased, so that an age trend is less apparent.

\section{Shift}

The absence rates of the men on day shift and night shift are shown in Table 2 . The men are matched by age and, as far as possible, job. There are no consistent differences in absence rates between those on permanent day shift and permanent night shift in the three work groups.

However, in groups A and B there appears to be more long-term absence and more time lost on the

TABLE 1

Annual Absence Rates of Men by Age Groups for Long Absences (LA) AND SHORT ABSENCES (SA)

\begin{tabular}{|c|c|c|c|c|c|c|c|c|}
\hline & & & \multicolumn{6}{|c|}{ Group } \\
\hline \multirow{2}{*}{\multicolumn{3}{|c|}{ Age (yr) }} & \multicolumn{2}{|c|}{$A$} & \multicolumn{2}{|c|}{$\boldsymbol{B}$} & \multicolumn{2}{|c|}{$C$} \\
\hline & & & $<40$ & $>40$ & $<40$ & $>40$ & $<40$ & $>40$ \\
\hline $\begin{array}{l}\text { Period prevalence rate (spells) LA } \\
\text { Average duration per spell (days) LA } \\
\text { Average duration per person (days) LA } \\
\text { Period prevalence rate (spells) SA } \\
\text { Proportion of time lost }(\%) \text {, all absence } \\
\text { No. of men } \quad \text {.. } \quad . . \quad \ldots \quad \ldots\end{array}$ & $\begin{array}{l}\cdots \\
\cdots \\
\cdots \\
\cdots \\
\cdots\end{array}$ & $\begin{array}{l}\cdots \\
\cdots \\
\cdots \\
\cdots \\
\cdots\end{array}$ & $\begin{array}{c}1 \cdot 05 \\
9 \cdot 9 \\
10 \cdot 4 \\
4 \cdot 44 \\
5 \cdot 67 \\
130\end{array}$ & $\begin{array}{c}0 \cdot 88 \\
11 \cdot 3 \\
9 \cdot 9 \\
3 \cdot 26 \\
4 \cdot 87 \\
196\end{array}$ & $\begin{array}{l}1 \cdot 52 \\
10 \cdot 3 \\
15 \cdot 7 \\
2 \cdot 86 \\
6 \cdot 12 \\
42\end{array}$ & $\begin{array}{c}1 \cdot 06 \\
13 \cdot 6 \\
14 \cdot 4 \\
1.99 \\
5 \cdot 22 \\
204\end{array}$ & $\begin{array}{c}0 \cdot 89 \\
17 \cdot 6 \\
15 \cdot 7 \\
5 \cdot 57 \\
6 \cdot 70 \\
282\end{array}$ & $\begin{array}{l}0 \cdot 76 \\
21 \cdot 5 \\
16 \cdot 4 \\
4 \cdot 20 \\
6 \cdot 57 \\
304\end{array}$ \\
\hline
\end{tabular}


TABLE 2

Annual Absence Rates of Men by Shift for Long Absences (LA) AND SHORT AbSENCES (SA)

\begin{tabular}{|c|c|c|c|c|c|c|c|c|}
\hline & & & \multicolumn{6}{|c|}{ Group } \\
\hline & & & \multicolumn{2}{|c|}{$A$} & \multicolumn{2}{|c|}{$B$} & \multicolumn{2}{|c|}{$C$} \\
\hline & & & Day & Night & Day & Night & Day & Night \\
\hline $\begin{array}{l}\text { Period prevalence rate (spells) LA } \ldots \\
\text { Average duration per spell (days) LA } \\
\text { Average duration per person (days) LA } \\
\text { Period prevalence rate (spells) SA } \\
\text { Proportion of time lost }(\%) \text {, all absence } \\
\text { No. of men } \quad . . \quad \ldots \quad \ldots\end{array}$ & $\begin{array}{l}\cdots \\
\cdots \\
\cdots \\
\cdots \\
\cdots\end{array}$ & $\begin{array}{l}\cdots \\
\cdots \\
\cdots \\
\cdots \\
\cdots\end{array}$ & $\begin{array}{c}0 \cdot 77 \\
12 \cdot 1 \\
9 \cdot 3 \\
3 \cdot 97 \\
4 \cdot 81 \\
163\end{array}$ & $\begin{array}{c}1 \cdot 13 \\
9 \cdot 7 \\
11 \cdot 0 \\
3 \cdot 49 \\
5 \cdot 58 \\
163\end{array}$ & $\begin{array}{c}0 \cdot 90 \\
13 \cdot 2 \\
11 \cdot 9 \\
2 \cdot 12 \\
4 \cdot 54 \\
123\end{array}$ & $\begin{array}{c}1 \cdot 38 \\
12 \cdot 6 \\
17 \cdot 4 \\
2 \cdot 16 \\
6 \cdot 38 \\
123\end{array}$ & $\begin{array}{c}0 \cdot 82 \\
19 \cdot 3 \\
15 \cdot 7 \\
5 \cdot 28 \\
6 \cdot 69 \\
293\end{array}$ & $\begin{array}{l}0 \cdot 84 \\
19 \cdot 7 \\
16 \cdot 5 \\
4 \cdot 45 \\
6 \cdot 83 \\
293\end{array}$ \\
\hline
\end{tabular}

TABLE 3

Annual Absence Rates of Men by Shift in Groups A and B for Long Absences (LA)

\begin{tabular}{|c|c|c|c|c|c|c|c|c|c|c|c|c|}
\hline & \multicolumn{12}{|c|}{ Group } \\
\hline & \multicolumn{6}{|c|}{$A$} & \multicolumn{6}{|c|}{$B$} \\
\hline & \multicolumn{2}{|c|}{$1962-3$} & \multicolumn{2}{|c|}{$1963-4$} & \multicolumn{2}{|c|}{$1964-5$} & \multicolumn{2}{|c|}{$1962-3$} & \multicolumn{2}{|c|}{$1963-4$} & \multicolumn{2}{|c|}{$1964-5$} \\
\hline & Day & Night & Day & Night & Day & Night & Day & Night & Day & Night & Day & Night \\
\hline $\begin{array}{l}\text { Period prevalence rate (spells) LA . } \\
\text { Average duration per spell (days) LA } \\
\text { Average duration per person (days) }\end{array}$ & $\begin{array}{c}0.67 \\
10.5 \\
\end{array}$ & $\begin{array}{l}1 \cdot 10 \\
8 \cdot 9\end{array}$ & $\begin{array}{c}0.71 \\
12 \cdot 6\end{array}$ & $\begin{array}{l}1.04 \\
9 \cdot 7\end{array}$ & $\begin{array}{c}0.94 \\
12.7\end{array}$ & $\begin{array}{l}1 \cdot 25 \\
10 \cdot 4\end{array}$ & $\begin{array}{c}0.78 \\
11.0\end{array}$ & $\begin{array}{c}1 \cdot 39 \\
12 \cdot 1\end{array}$ & $\begin{array}{c}0.95 \\
13.5\end{array}$ & $\begin{array}{c}1 \cdot 29 \\
12 \cdot 8\end{array}$ & $\begin{array}{c}0.98 \\
14.6\end{array}$ & $\begin{array}{c}1.46 \\
13.0\end{array}$ \\
\hline $\begin{array}{llllll}\text { LA } & \ldots & \ldots & \ldots & \ldots & \ldots\end{array}$ & $7 \cdot 1$ & $9 \cdot 8$ & $8 \cdot 9$ & $10 \cdot 1$ & $11 \cdot 9$ & $13 \cdot 0$ & $8 \cdot 6$ & $16 \cdot 8$ & $12 \cdot 8$ & $16 \cdot 5$ & $14 \cdot 2$ & $18 \cdot 9$ \\
\hline
\end{tabular}

night shift, although the average duration of absence per spell is rather less on this shift. For short-term absence there are no consistent trends. It is necessary to test if the observed differences in groups $\mathbf{A}$ and $\mathbf{B}$ are consistent; accordingly, the absence rates of the day shift and night shift were calculated for each recorded year. Table 3 suggests that on the night shift in both work groups there are more absences of four days or over, and the average duration per person is greater. However, the average length of the spells is generally less on the night shift. A similar analysis was carried out by age group and the same trends were consistently observed in groups A and $B$ but were absent in group C.

\section{Sickness diagnosis}

For groups A and B the sickness diagnoses were recorded from the medical certificates supplied by general practitioners and hospitals. The number of absences per man under the commoner diagnoses are shown in Table 4 for the night shift and day shift in groups A and B combined. All types of diagnosed illness are more prevalent on the night shift than on the day shift, and the increased absence on the night shift is not, therefore, due to the predominance of any particular categories of illness.
TABLE 4

Mean Number of Spells of Absence Per Man-year by Cause of Sickness for Groups A aNd B

\section{COMBINED}

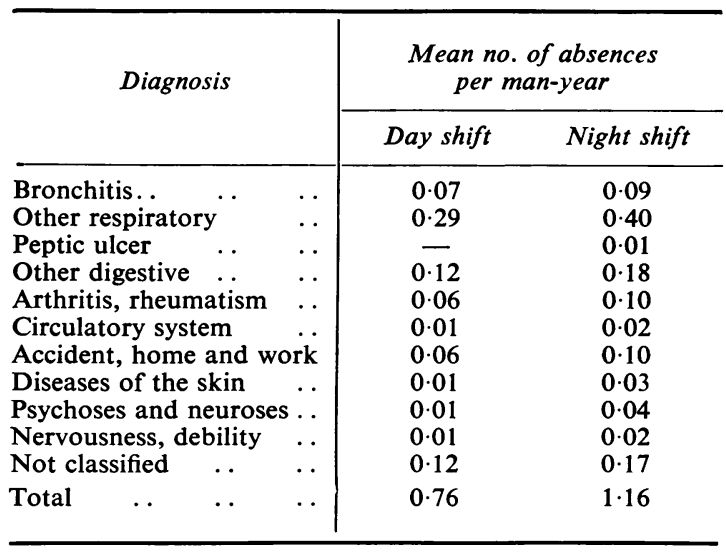

\section{Attendance and overtime working}

When attempting to relate absence from work and attendance, two problems arose in the measurement 
of attendance. Firstly, it was necessary to arrive at a measure of attendance which was, as far as possible, independent of absence because, when absence is long-term or frequent in a period then, clearly, total attendance must be reduced. Consequently, the average hours worked in a full week (Hw) were calculated for each man in group $\mathrm{C}$ by applying the formula:

$$
H w=\frac{H}{w-A}
$$

where $\mathrm{Hw}$ represents the average hours worked in a full week, $\mathbf{H}$ the total annual actual hours worked, $\mathrm{W}$ the planned working weeks in a year, and $\mathrm{A}$ the weeks absent. From the results the men were then divided into high, medium, and low overtime groups with approximately equal numbers in each.

The second problem was that the only measure related to attendance in groups A and B which it was practical to record was the overtime earnings, but their relationship to overtime hours is not direct because overtime rates vary on different days of the week and according to the amount of overtime worked. For both groups the actual hours worked were recorded from the daily work sheets for small samples of the men; the actual hours worked in a full week were calculated and the men were ranked in order of attendance. The average overtime earnings in a full working week were also calculated for these small samples of men and they were arranged in rank order. The rank correlation (tau) for day shift and night shift separately ranged from +0.89 to +0.97 in the different groups. In view of these very high correlations between hours worked and overtime earnings it was possible to group the men into high, medium, and low overtime groups from the average overtime earnings in a full week, with confidence.

Table 5 shows, for one year of the survey, the number of men in the three overtime groups and the mean weekly hours worked in a full week. The hours are total attendance figures, inclusive of meal breaks, which are actual hours for group $\mathrm{C}$ but estimated for groups $\mathrm{A}$ and $\mathrm{B}$. The Table shows a wide range of hours which were at a high level in $A$ and $B$ but less in C. Overtime was generally voluntary, although in group B if a man chose to work on certain shift systems he was required to work overtime.

The crude absence rates for the different overtime groups are shown in Table 6. For absences of four days or more, men in the high overtime group have lower rates on all indices than men in the medium and low overtime groups. There is no consistent

TABLE 5

Number of Men and Mean Hours worked in a Full Week in Three Overtime Groups

\begin{tabular}{|c|c|c|c|c|c|c|c|c|c|c|c|c|}
\hline \multirow[b]{3}{*}{ Overtime } & & & & \multicolumn{9}{|c|}{ Group } \\
\hline & & & & \multicolumn{3}{|c|}{$A$} & \multicolumn{3}{|c|}{$\boldsymbol{B}$} & \multicolumn{3}{|c|}{$C^{1}$} \\
\hline & & & & High & Med. & Low & High & Med. & Low & High & Med. & Low \\
\hline $\begin{array}{l}\text { Mean hours worked } \\
\text { No. of men }\end{array}$ & $\begin{array}{l}\ldots \\
\ldots\end{array}$ & $\begin{array}{l}\ldots \\
\ldots\end{array}$ & $\begin{array}{l}\cdots \\
\cdots\end{array}$ & $\begin{array}{r}63 \\
102\end{array}$ & $\begin{array}{r}55 \\
122\end{array}$ & $\begin{array}{r}45 \\
102\end{array}$ & $\begin{array}{r}59 \\
102\end{array}$ & $\begin{array}{l}50 \\
68\end{array}$ & $\begin{array}{l}44 \\
76\end{array}$ & $\begin{array}{r}53 \\
171\end{array}$ & $\begin{array}{r}48 \\
210\end{array}$ & $\begin{array}{r}45 \\
201\end{array}$ \\
\hline
\end{tabular}

${ }^{1}$ Hours worked not available for four men.

TABLE 6

Annual Absence Rates of Men in High, Medium, and Low Overtime Groups for LoNg AbSENCes (LA) AND SHort AbSENCES (SA)

\begin{tabular}{|c|c|c|c|c|c|c|c|c|c|}
\hline \multirow[b]{3}{*}{ Overtime } & \multicolumn{9}{|c|}{ Group } \\
\hline & \multicolumn{3}{|c|}{$A$} & \multicolumn{3}{|c|}{$B$} & \multicolumn{3}{|c|}{$C$} \\
\hline & High & Med. & Low & High & Med. & Low & High & Med. & Low \\
\hline $\begin{array}{l}\text { Period prevalence rate (spells) LA } \ldots \\
\text { Average duration per spell (days) LA. } \\
\text { Average duration per person (days) LA } \\
\text { Period prevalence rate (spells) SA } \ldots \\
\text { Proportion of lost time (\%), all absence }\end{array}$ & $\begin{array}{l}0 \cdot 88 \\
9 \cdot 7 \\
8 \cdot 5 \\
3 \cdot 73 \\
4 \cdot 75\end{array}$ & $\begin{array}{c}1 \cdot 01 \\
10 \cdot 6 \\
10 \cdot 7 \\
3 \cdot 87 \\
5 \cdot 48\end{array}$ & $\begin{array}{c}0 \cdot 94 \\
11 \cdot 3 \\
10 \cdot 7 \\
3 \cdot 56 \\
5 \cdot 36\end{array}$ & $\begin{array}{c}1 \cdot 07 \\
12 \cdot 0 \\
12 \cdot 8 \\
2 \cdot 24 \\
5 \cdot 05\end{array}$ & $\begin{array}{c}1 \cdot 14 \\
13 \cdot 0 \\
14 \cdot 9 \\
2 \cdot 24 \\
5 \cdot 43\end{array}$ & $\begin{array}{c}1 \cdot 21 \\
13 \cdot 2 \\
16 \cdot 0 \\
1.94 \\
5 \cdot 69\end{array}$ & $\begin{array}{c}0 \cdot 74 \\
15 \cdot 2 \\
11 \cdot 3 \\
4 \cdot 39 \\
5 \cdot 08\end{array}$ & $\begin{array}{l}0 \cdot 77 \\
21 \cdot 3 \\
16 \cdot 4 \\
4 \cdot 52 \\
6 \cdot 61\end{array}$ & $\begin{array}{c}0 \cdot 94 \\
19 \cdot 6 \\
18 \cdot 5 \\
5 \cdot 64 \\
7 \cdot 88\end{array}$ \\
\hline
\end{tabular}


difference between the last two groups; similarly, there are no consistent differences between the groups in spells of short-term absence.

To find out if the lower long-term absence among the men on high overtime was consistently so, the absence rates were calculated for men in the different overtime groups by age and by shift. As the number of men in each five-year age group was not sufficient to allow the calculation of standardized rates the samples were divided into men under 40 and those of 40 and over. When tabulated in these ways the results were not consistent, nor was the number of men without long absences different between the overtime groups, but the results did not suggest that high overtime was associated with high absence. Indeed, Table 7, which shows the absence rates of men in the different overtime groups by age, would suggest that overtime and absence are on the whole negatively associated. It is particularly noteworthy that high overtime is not associated with short-term absence. The numbers of men in each group are small, although the figures are for three years for groups $\mathbf{A}$ and $\mathbf{B}$.

\section{Other variables}

It was important to test if other variables were associated with working on the day shift and night shift or in high and low overtime groups. The first variable examined was family responsibilities as indicated by the income tax code number. Buck and Shimmin (1959) and Nuttall (1967) have shown that, at the status level considered here, income tax code number is a good indicator of marital state and number of children. Accordingly, the samples were divided into five income tax code groups which, on the basis of tax allowances, would correspond to single men, married, married with one child, married with two children, and married with three or more children. Even when a man is allocated to the wrong group for reasons such as an allowance for the interest on a house mortgage it is still possible to think of income tax code numbers as a measure of domestic financial responsibility.

Table 8 shows the numbers of men on the day shift and night shift in the different family responsibility groups for all three undertakings combined. The null hypothesis of equal frequencies in the two groups can easily be rejected $\left(\chi^{2}=42 \cdot 47\right.$, D.F. $=4$, $P<0.001)$, and inspection shows that there are fewer single men and married men with no children on the night shift than on the day shift, but a greater number of men with four or more dependants on the night shift.

Table 9 shows the numbers of men on high, medium, and low overtime in the different family responsibility groups for all three undertakings com-

TABLE 7

Annual Absence Rates of Men in High, Medium, and Low Overtime Groups BY AGE (UNDER 40 AND 40 AND OVER)

\begin{tabular}{|c|c|c|c|c|c|c|c|c|c|c|c|c|c|c|}
\hline \multirow{3}{*}{\multicolumn{2}{|c|}{ Overtime }} & & & & & \multicolumn{9}{|c|}{ Group } \\
\hline & & & & & & \multicolumn{3}{|c|}{$A$} & \multicolumn{3}{|c|}{$\boldsymbol{B}$} & \multicolumn{3}{|c|}{$C$} \\
\hline & & & & & & High & Med. & Low & High & Med. & Low & High & Med. & Low \\
\hline \multicolumn{6}{|c|}{ Period prevalence rate (spells) LA } & & & & & & & & & \\
\hline $\begin{array}{l}<40 \\
>40\end{array}$ & $\begin{array}{l}\ldots \\
\ldots\end{array}$ & $\begin{array}{l}\cdots \\
\ldots\end{array}$ & $\begin{array}{l}. \\
.\end{array}$ & . & $\begin{array}{l}\ldots \\
\ldots\end{array}$ & $\begin{array}{l}1 \cdot 14 \\
0 \cdot 69\end{array}$ & $\begin{array}{l}1.06 \\
0.97\end{array}$ & $\begin{array}{l}0.93 \\
0.95\end{array}$ & $\begin{array}{r}(1.36 \\
0.99\end{array}$ & $\begin{array}{l}1.76 \\
1.05\end{array}$ & $\begin{array}{l}1 \cdot 50) \\
1 \cdot 15\end{array}$ & $\begin{array}{l}0.74 \\
0.75\end{array}$ & $\begin{array}{l}0.90 \\
0.66\end{array}$ & $\begin{array}{l}0.98 \\
0.80\end{array}$ \\
\hline \multicolumn{6}{|c|}{ Average duration per spell (days) LA } & & & & & & & & & \\
\hline $\begin{array}{l}<40 \\
>40\end{array}$ & $\begin{array}{l}\ldots \\
\ldots\end{array}$ & . & $\begin{array}{l}. \\
\cdots\end{array}$ & 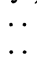 & $\begin{array}{l}. \\
\ldots\end{array}$ & $\begin{array}{r}9 \cdot 2 \\
10 \cdot 3\end{array}$ & $\begin{array}{l}10 \cdot 4 \\
10 \cdot 7\end{array}$ & $\begin{array}{r}9 \cdot 8 \\
12 \cdot 1\end{array}$ & $\begin{array}{l}(10 \cdot 3 \\
12 \cdot 6\end{array}$ & $\begin{array}{r}9 \cdot 8 \\
13 \cdot 9\end{array}$ & $\begin{array}{l}10 \cdot 7) \\
13 \cdot 9\end{array}$ & $\begin{array}{l}14 \cdot 2 \\
15 \cdot 9\end{array}$ & $\begin{array}{l}18 \cdot 5 \\
24 \cdot 7\end{array}$ & $\begin{array}{l}17 \cdot 8 \\
24 \cdot 8\end{array}$ \\
\hline \multicolumn{6}{|c|}{ Average duration per person (days) LA } & & & & & & & & & \\
\hline $\begin{array}{l}<40 \\
>40\end{array}$ & $\begin{array}{l}\ldots \\
.\end{array}$ & $\begin{array}{l}. \\
\ldots\end{array}$ & $\begin{array}{l}. . \\
.\end{array}$ & $\begin{array}{l}. \\
.\end{array}$ & $\begin{array}{l}. \\
\ldots\end{array}$ & $\begin{array}{r}10 \cdot 5 \\
7 \cdot 1\end{array}$ & $\begin{array}{l}11 \cdot 1 \\
10 \cdot 4\end{array}$ & $\begin{array}{r}9 \cdot 1 \\
11 \cdot 6\end{array}$ & $\begin{array}{l}(14.0 \\
12.5\end{array}$ & $\begin{array}{l}17 \cdot 2 \\
14 \cdot 5\end{array}$ & $\begin{array}{l}16 \cdot 0) \\
16 \cdot 0\end{array}$ & $\begin{array}{l}10.4 \\
11.9\end{array}$ & $\begin{array}{l}16 \cdot 6 \\
16 \cdot 2\end{array}$ & $\begin{array}{l}17 \cdot 5 \\
19 \cdot 8\end{array}$ \\
\hline \multicolumn{6}{|c|}{ Period prevalence rate (spells) SA } & & & & & & & & & \\
\hline $\begin{array}{l}<40 \\
>40\end{array}$ & $\begin{array}{l}\cdots \\
\cdots\end{array}$ & $\begin{array}{l}\cdots \\
\cdots\end{array}$ & $\begin{array}{l}. \\
. .\end{array}$ & $\begin{array}{l}\ldots \\
\ldots\end{array}$ & $\begin{array}{l}\ldots \\
\ldots\end{array}$ & $\begin{array}{l}4 \cdot 30 \\
3 \cdot 34\end{array}$ & $\begin{array}{l}3 \cdot 31 \\
3 \cdot 31\end{array}$ & $\begin{array}{l}4 \cdot 31 \\
3 \cdot 12\end{array}$ & $\begin{array}{r}(3.32 \\
1.96\end{array}$ & $\begin{array}{l}3 \cdot 00 \\
2 \cdot 12\end{array}$ & $\begin{array}{l}2 \cdot 21) \\
1 \cdot 88\end{array}$ & $\begin{array}{l}4 \cdot 56 \\
4 \cdot 28\end{array}$ & $\begin{array}{l}5 \cdot 27 \\
3 \cdot 86\end{array}$ & $\begin{array}{l}6 \cdot 46 \\
4 \cdot 58\end{array}$ \\
\hline \multicolumn{6}{|c|}{$\%$ lost time, all absence } & & & & & & & & & \\
\hline $\begin{array}{l}<40 \\
>40\end{array}$ & $\begin{array}{l}\ldots \\
\ldots\end{array}$ & $\begin{array}{l}\cdots \\
\ldots\end{array}$ & $\begin{array}{l}. \\
\ldots\end{array}$ & $\begin{array}{l}\ldots \\
\ldots\end{array}$ & $\begin{array}{l}\ldots \\
\ldots\end{array}$ & $\begin{array}{l}5 \cdot 67 \\
4 \cdot 11\end{array}$ & $\begin{array}{l}6.04 \\
5 \cdot 07\end{array}$ & $\begin{array}{l}5 \cdot 32 \\
5 \cdot 38\end{array}$ & $\begin{array}{r}(5.88 \\
4.84\end{array}$ & $\begin{array}{l}6 \cdot 34 \\
5 \cdot 28\end{array}$ & $\begin{array}{l}6 \cdot 04) \\
5 \cdot 61\end{array}$ & $\begin{array}{l}4 \cdot 84 \\
5 \cdot 24\end{array}$ & $\begin{array}{l}6 \cdot 95 \\
6 \cdot 30\end{array}$ & $\begin{array}{l}8 \cdot 01 \\
7 \cdot 70\end{array}$ \\
\hline
\end{tabular}

Numbers appearing in parentheses are too small for reliable figures. 
TABLE 8

Numbers of Men in Different Income Tax Code Groups on Day Shift and Night Shift

\begin{tabular}{|c|c|c|c|c|c|c|c|c|c|}
\hline \multirow{2}{*}{\multicolumn{4}{|c|}{ I.T.C. groups }} & \multicolumn{6}{|c|}{ No. of dependants } \\
\hline & & & & 0 & 1 & 2 & 3 & 4 or more & Total \\
\hline $\begin{array}{l}\text { Day shift ... } \\
\text { Night shift }\end{array}$ & $\begin{array}{l}\ldots \\
\ldots\end{array}$ & $\begin{array}{l}\ldots \\
\ldots\end{array}$ & $\begin{array}{l}\cdots \\
\cdots\end{array}$ & $\begin{array}{r}125 \\
86\end{array}$ & $\begin{array}{l}187 \\
148\end{array}$ & $\begin{array}{l}124 \\
117\end{array}$ & $\begin{array}{r}84 \\
100\end{array}$ & $\begin{array}{r}55 \\
128\end{array}$ & $\begin{array}{l}575 \\
579\end{array}$ \\
\hline
\end{tabular}

TABLE 9

Numbers of Men in Different Income Tax Code Groups working High, Medium, AND Low OVERTIME Hours

\begin{tabular}{|c|c|c|c|c|c|c|c|c|}
\hline \multirow{2}{*}{\multicolumn{3}{|c|}{ I.T.C. groups }} & \multicolumn{6}{|c|}{ No. of dependants } \\
\hline & & & \multirow{2}{*}{\begin{tabular}{r}
\multicolumn{1}{c}{0} \\
45 \\
57 \\
109
\end{tabular}} & \multirow{2}{*}{$\begin{array}{c}1 \\
103 \\
117 \\
115\end{array}$} & \multirow{2}{*}{$\begin{array}{l}2 \\
81 \\
85 \\
75\end{array}$} & \multirow{2}{*}{$\begin{array}{l}3 \\
76 \\
73 \\
35\end{array}$} & \multirow{2}{*}{$\begin{array}{c}4 \text { or more } \\
69 \\
68 \\
46\end{array}$} & \multirow{2}{*}{$\begin{array}{c}\text { Tota } \\
374 \\
400 \\
380\end{array}$} \\
\hline $\begin{array}{l}\text { High overtime } . \\
\text { Medium overtime } \\
\text { Low overtime } \quad . .\end{array}$ & $\begin{array}{l}\ldots \\
\cdots \\
\ldots\end{array}$ & $\begin{array}{l}\ldots \\
\cdots \\
\ldots\end{array}$ & & & & & & \\
\hline
\end{tabular}

bined. Similarly, the null hypothesis of equal frequencies in the three groups can be rejected $\left(\chi^{2}=\right.$ 56.87, D.F. $=8, \mathrm{P}<0.001$ ), and inspection shows that there are fewer single men in the high and medium overtime groups and relatively few men with two or more children in the low overtime group. The distributions of the high and medium overtime groups are very similar.

The conclusions in both Tables were verified by examining the income tax code numbers of the men in each undertaking separately and for the men under $\mathbf{4 0}$ and those of $\mathbf{4 0}$ years of age and more. In general, the trends were consistent and application of the $\chi^{2}$ test showed significance. It seemed that increased domestic responsibilities were associated with more overtime working and a tendency to work on the night shift. Single status was associated with an avoidance of high overtime and night shift, and married men with no children also tended to avoid the night shift.

The second variable examined which might have been associated with shift work was length of service. In two of the undertakings, working on permanent nights was by choice and, as there were waiting lists for the night shift, allocation was by seniority. It might be expected that the length of service of night shift workers would be longer. However, analysis showed that there was no difference in the length of service of men on the two shifts, although it must be noted that the analysis was completed not on the populations but on the samples which were matched for age and accordingly to some extent for length of service.
Finally, attempts were made to assess the work load on the day shift and night shift. In group $A$ it was possible to obtain the units of work handled per man-hour during the day and at night for four sections of the work, and the production figures are shown in Table 10.

TABLE 10

Group A: UnITS OF WORK DURING DAY AND AT Night for Four Sections, Average of Three SHIFTS

\begin{tabular}{c|cc|c}
\hline \multirow{3}{*}{ Section } & \multicolumn{2}{|c|}{ Units of work per man-hour } & \multirow{2}{*}{$\begin{array}{l}\text { Night as } \\
\% \text { of day }\end{array}$} \\
\cline { 2 - 3 } & Day & Night & \\
\hline A & 21.42 & 13.08 & $61 \cdot 1$ \\
B & 25.61 & 14.65 & 57.2 \\
C & 17.86 & 14.56 & 81.5 \\
D & 21.86 & 12.55 & 57.4 \\
\hline
\end{tabular}

For these examples fewer units were handled per man-hour by the night staff, although the figures do not illustrate the variations in work load within the night duty period where bursts of busy periods alternated with slack periods. In group B no output records were available, although it was generally believed that pressure of work was less during the night than by day. In group $\mathrm{C}$ efficiency percentages derived from time study standards were compared on the day shift and the night shift for 29 machine 
processes over a four-week period. The mean percentage efficiencies and their standard deviations are shown below, and it is seen that there was no difference in productivity on the two shifts:

Group C: Productivity on 29 processes for a four-week period

$\begin{array}{lcc} & \text { Day shift } & \text { Night shift } \\ \text { Mean efficiency, \% } & 73.2 & 74 \cdot 2 \\ \text { SD } & 9.55 & 8.43\end{array}$

\section{Discussion}

The study showed that when the absence rates of permanent day workers and permanent night workers were compared, the long-term absence was higher on the night shift in two groups, but in a third group, an engineering works, there was no difference in absence on the two shifts. There was no difference in short-term absence between shifts. It is interesting to compare these results with studies of absence among rotating shift workers who have been shown to have lower absence rates than comparable day workers. Aanonsen (1964), in a longitudinal study and in a cross-sectional study, recorded the sickness absence of men who had transferred from shift work to day work, and their sickness absence rates tended to resemble the day workers' rates and were higher than those of the men on shift work. This suggested that selection led to the low sickness absence among the shift workers. Taylor (1967) found that shift workers had higher job satisfaction, liked shift work, and worked in small groups, so that personal involvement in the work and social factors may account for low absence among rotating shift workers, in addition to selection.

In the present study, as there was no consistent difference between the shifts, it cannot be argued that permanent night work was necessarily associated with more absence. In the two undertakings where long-term absence was higher on the night shift there was a higher prevalence of all the major types of illness, and it seems unlikely that permanent night work could have caused this. If the increase had been confined to certain illnesses such as gastrointestinal or nervous disorders, which have previously been associated with shift work (Menzel, 1962), then the causal link between night work and absence would have been probable, but this was not the case. A previous paper (de la Mare and Walker, 1968) reported the results of interviews with a small sample of men in group A, and it was shown that permanent night workers were highly satisfied, had chosen night work, and appreciated the less stressful atmosphere on the night shift. Poor morale was not associated with the high long-term absence in this group.

The high absence on the night shift occurred in the two undertakings with a lighter work load during the night than by day, whereas absence was similar on the two shifts in the undertakings where the work load by day and at night was the same. It is possible that a number of men liable to frequent longer absence had chosen to work on the night shift where the pace of work was less arduous and the atmosphere less rushed than by day, whereas when there was no difference in the work load on the two shifts the advantage to these men in choosing to work nights was absent. It is possible, therefore, that selfselection was the reason for high absence in two work groups on the night shift, and that permanent night work of itself is not associated with high absence. If this explanation is correct then the present results do not conflict with the suggestion that a long period on nights may be desirable. The need in this field is for longitudinal studies following through a cohort of men for a number of years, although this paper suggests that a longitudinal study in one organization could not necessarily be generalized to others.

The most interesting result of the study is the lack of a relationship between absence from work and overtime. As the working of overtime was voluntary, it was possible for an individual to adjust his hours of work, to some extent, to suit his financial needs and his capacity for work, and the results might have been different if the overtime working had been compulsory. With a general increase in hours of work or compulsory overtime an increase in the level of absence might be expected, and previous research (Medical Research Council, 1942) has demonstrated that this is so. However, Lokander (1962) found no systematic relation between overtime and sickness absence, and Buzzard and Liddell (1963) have shown results similar to our own in that coal miners who worked high overtime and many Saturday shifts tended to have least absence during the normal working week. Management commonly believes that high overtime is associated with high absence, particularly short-term absence, and many of the managers of the three working groups alleged that high overtime and high absence were linked, but there was no evidence of this at all. It might be argued that this lack of association was due to the success of the disciplinary methods used to reduce high casual absence. However, it seems more probable that the number of overtime hours were within the tolerance limits of those who had chosen to work them.

The lack of association between absence and overtime working suggests that a reappraisal of the value of voluntary overtime may be overdue. More research is required, but the assumption that all overtime need necessarily be undesirable (Whybrew, 1968) requires a detailed examination. The present levels of overtime may be within the capacity of the operative on most types of work.

An interesting side-light on the working of over- 
time and night work was their association with the domestic financial responsibilities of shift workers. Shepherd and Walker (1958), Buck and Shimmin (1959), and Shimmin and de la Mare (1964) have discussed the relationship between overtime and financial responsibilities, and the underlying motivational variables; it seems that the same kind of relationship exists between working a permanent night shift and family responsibilities. Single men and married men without children tend to avoid permanent night shift, whereas men with three or more children tend to work it.

A notable feature of the hours of work in the three undertakings was their flexibility. Provided sufficient men voluntarily staff the fixed night shift, those who cannot tolerate night work may avoid it and work either fixed or alternating day shifts. As shortened hours of work provide an opportunity tor developing systems other than the traditional three-shift weekly rotating type, it becomes important to follow up alternative ways of arranging continuous shift hours, including permanent night work.

\section{References}

Aanonsen, A. (1964). Shift Work and Health. Norwegian Monograph on Medical Science, Oslo.

Andlauer, P., and Fourré, L. (1962). Aspects Ergonomiques du Travail en Equipes Alternantes, pp. 28-38. Centre d'Etudes de Physiologie Appliquée au Travail de Strasbourg.

Bjerner, B., Holm, $\AA$., and Swensson, Å. (1955). Diurnal variation in mental performance. A study of three-shift workers. Brit. J. industr. Med., 12, 103-110.

Browne, R. C. (1949). The day and night performance of teleprinter switchboard operators. Occup. Psychol., 23, 121-126.

Buck, L., and Shimmin, S. (1959). Overtime and financial responsibility. Occup. Psychol., 33, 137-148.

Buzzard, R. B., and Liddell, F. D. K. (1963). Coalminers' Attendance at Work, p. 54. Medical Research Memorandum No. 3. National Coal Board.

Colquhoun, W. P., Blake, M. J. F., and Edwards, R. S. (1968a). Experimental studies of shift work. I: A comparison of 'rotating' and 'stabilized' 4-hour shift systems. Ergonomics, 11, 437-453.

- and - (1968b). Experimental studies of shift work. II: Stabilized 8-hour shift systems. Ergonomics, 11, 527-546.

Gordon, C., Emerson, A. R., and Pugh, D. S. (1959). Patterns of sickness absence in a railway population. Brit. J. industr. Med., 16, 230-243.

Kleitman, N. (1952). Sleep. Sci. Amer., 187, November, pp. 34-38.

(1963). Sleep and Wakefulness. 2nd ed., p. 317. University of Chicago Press.
- , and Jackson, D. P. (1950). Body temperature and performance under different routines. J. appl. Physiol., 3, 309-328.

Lokander, S. (1962). Sick absence in a Swedish company, p. 130. Acta med. scand., 171, Suppl. 377.

London Transport Executive (1956). Health in Industry - A Contribution to the Study of Sickness Absence, p. 33. Butterworth, London.

de la Mare, G., and Walker, J. (1968). Factors influencing the choice of shift rotation. Occup. Psychol., 42, 1-21.

Medical Research Council (1942). Hours of Work, Lost Time and Labour Wastage. Emergency Rep. Industr. Hlth Res. Bd. (Lond.), No. 2, H.M.S.O.

Menzel, W. (1962). Menschliche Tag - Nacht - Rhythmik und Schichtarbeit, pp. 122-134. Benno Schwabe, Basel/ Stuttgart.

Mills, J. N. (1966). Human circadian rhythms. Physiol. Rev., 46, 128-171.

Ministry of Labour (1965). Shift working. Ministry of Labour Gazette, 73, 148-155.

Ministry of Munitions (1917). Industrial Efficiency and Fatigue. Health of Munition Workers Committee. Interim Report Cmnd. 8511. H.M.S.O., London.

Nuttall, J. F. (1967). Are tax codes useful for personnel records? National Institute of Industrial Psychology Bull., Feb., pp. 32-34.

Raffle, P. A. B. (1970). Personal communication.

Shepherd, R. D., and Walker, J. (1958). Absence from work in relation to wage level and family responsibility. Brit. $J$. industr. Med., 15, 52-61.

Shimmin, S., and de la Mare, G. (1964). Individual differences in overtime working. Occup. Psychol., 38, 37-47.

Taylor, P. J. (1967). Shift and day work. A comparison of sickness absence, lateness, and other absence behaviour at an oil refinery from 1962 to 1965 . Brit. J. industr. Med., 24, 93-101.

(1968a). Personal factors associated with sickness absence. A study of 194 men with contrasting absence experience in a refinery population. Brit. J. industr. Med., 25, 106-118.

- (1968b). In Proceedings of the Symposium on Absence from Work Attributed to Sickness, edited by A. Ward Gardner, pp. 71-75. Society of Occupational Medicine, London.

Teleky, L. (1943). Problems of night work: influences on health and efficiency. Industr. Med., 12, 758-779.

Thiis-Evensen, E. (1958). Shift work and health. Industr. Med. Surg., 27, 493-497.

Utterback, R. A., and Ludwig, G. D. (1949). A comparative study of schedules for standing watches aboard submarines based on body temperature cycles. Nav. Med. Res. Inst., Bethesda, Md., Rep. No. 1, Project NM 004003.

van Loon, J. H. (1963). Diurnal body temperature curves in shift workers. Ergonomics, 6, 267-273.

Wyatt, S., and Marriott, R. (1953). Night work and shift changes. Brit. J. industr. Med., 10, 164-172.

Whybrew, E. G. (1968). Overtime Working in Britain. Research Paper 9. Royal Commission on Trade Unions and Employers Associations. H.M.S.O., London.

Received for publication April 12, 1970. 